\title{
LA NOSTALGIA COMO EFUGIO AL ESTADO DE ANGUSTIA
}

\author{
Jorge Montesó-Ventura \\ bttp://orcid.org/0000-0002-0970-9652 \\ Centre d'Estudis Antropològics ACAF \\ bttps://doi.org/10.15304/ag.40.2.6775
}

\section{Resumen}

En los últimos años, al menos en las llamadas sociedades occidentales, se ha consolidado una clara tendencia a consumir productos que pretenden promover un estado de nostalgia en el consumidor: moda, cine, televisión... Todo lo que atañe al consumo de masas, en su estética, se viste con elementos que intentan evocar parte del pasado de su target, y funciona. En este artículo analizaremos, entendiendo el consumo solo como la expresión más patente, qué nos motiva a buscar estímulos que evoquen el pasado, qué nos empuja a él y cuánto tiene que ver en ello el estado de angustia al que nos arrastra el tipo de circunstancia que vivimos. Intentaremos demostrar cómo la nostalgia, más allá de tópicos, se ofrece como el efugio más accesible y eficaz para enmascarar temporalmente esa angustia provocada por un medio percibido como inhóspito y fragmentado, y sin necesidad de renunciar a sí mismo.

Palabras clave: nostalgia, angustia, pasado, circunstancia, soledad, fenomenología.

\begin{abstract}
In recent years, at least in the so-called western societies, a clear trend has been established to consume products that aim to promote a state of nostalgia in the consumer: fashion, cinema, television... everything that concerns mass consumption, in its aesthetics, it dresses with elements that try to evoke part of its target's past, and it works. In this article we will analyse, understanding consumption only as the most obvious expression, what motivates us to seek stimuli that evoke the past, what pushes us to it and how much does the
\end{abstract}

Recibido: 23/04/2020. Aceptado: 30/06/2020. 
state of anguish to which the type of circumstance draws us have to do with it that we live. We will try to demonstrate how nostalgia, beyond topics, is offered as the most accessible and effective refuge to temporarily mask that anguish caused by a medium perceived as inhospitable and fragmented, and without the need to renounce itself.

Keywords: nostalgia, anxiety, past, circumstance, loneliness, phenomenology.

\section{Introducción}

Solo hay que pasearse una tarde por un centro comercial de cualquier ciudad europea para advertir, sin ningún tipo de dificultad, el gran surtido de estímulos evocadores de tiempos pasados que nutren los escaparates y paneles publicitarios de todos ellos. Toda clase de elementos promocionales, productos y ornamentaciones giran en torno a un claro intento por inspirar efluvios de épocas pasadas. Y es que, sin duda alguna, la nostalgia $v_{\text {vende }}{ }^{1}$, lo viejo y pasado remueve más que nunca la víscera de la llamada clase media marcando las líneas de producción del consumo de ocio y moda en nuestros días ${ }^{2}$. Revistas como Elle o Vogue hablan de lo nostálgico como la tendencia más fuerte de la última década en moda ${ }^{3}$. Si hablamos de cine, de las treinta películas más taquilleras del 2019, veinte fueron remakes de cintas de culto o sagas eternas que apelaban directamente a lo nostálgico ${ }^{4}$,

${ }^{1}$ No es una premisa flamante, en los 90 ya se realizaban estudios que demostraban el peso de lo nostálgico en las elecciones comerciales: W. J. Havlena y S. L. Holak, «The good old days: observations on nostalgia and its role in consumer behaviour", en R. H. Holman y R. Solomon (Eds.). Advances in consumer research, Provo, UT: ACR, 1991, pp. 323-329; S. Brown, "Retro-marketing: yesterday's tomorrows, today!», Marketing intelligence \& planning17/7 (1999), pp. 363-376. Ya más recientemente: U. R. Orth y A. Bourrain, «The influence of nostalgic memories on consumer exploratory tendences: Echoes from scents past», Journal of retailing and consumer services15/4(2008), pp. 277-287; D. D. Muehling, «The relative influence of advertising-evoked personal and historical nostalgic thoughts on consumer's Brand attitudes», Journal of marketing communications 19/2(2011), pp. 98-113.

${ }^{2}$ Ver en C. P. Valero e I. Zacipa, «El pasado está de moda. La nostalgia del consumo», en Zacipa, I., V. Tur-Viñes y J. Segarra-Saavedra (Eds.), Tendencias publicitarias en Iberoamérica. Diálogo de saberes y experiencias, Alacant: Universitat d'Alacant, 2016.

${ }^{3}$ S. Villaseñor, "Porqué la nostalgia es la tendencia más fuerte de la última década», Elle, 18/10/2018. [En línea]: https://elle.mx/moda/2018/10/18/nostalgia-de-moda-jovenes/; S. Yotka, «La nostalgia es, oficialmente, la tendencia de moda más importante de 2018», Vogue, 19/12/2018. [En línea]:https://www.vogue.mx/moda/tendencias/articulos/tendencias-de-moda-2018-nostalgia-segun-busquedas-de-google/14309

${ }^{4}$ J. Tones, «49 películas y series que nos harán celebrar la llegada de 2019», Xataka, 3/1/2019. [en línea] https://www.xataka.com/cine-y-tv/49-peliculas-series-que-nos-harancelebrar-llegada-2019 
fundamentalmente orientadas a captar un público nacido a finales de los 70 o primeros de los 80 - lo que no es casual si atendemos a la capacidad adquisitiva de estos ${ }^{5}$ - No hace falta ya ni hablar de lo tecnológico, donde móviles y videoconsolas de los 80 o 90 parecen ser ahora lo más deseado en plataformas de venta online; o de la industria literaria y musical que, en su nivel main stream, no parecen alcanzar más que a personajes obsoletos, sumergidos en el ideario popular, para volver a lanzarlos, a poder ser en formatos que muchos habíamos enterrado ya como casetes, vinilos, VHS, etc. ${ }^{6}$.

Todo, todo lo referente al consumo popular parece estar infectado de arrebatos nostálgicos lo que, evidentemente, no es producto del azar. Este impulso indica algo, sugiere un sentir más profundo que el simple arrastre por darse un capricho o compartir un rato de ocio con los seres queridos. Podría parecer que indica una falta de creatividad por parte de artistas o diseñadores, idea que entroncaría con la crisis que ha afectado a la moderna idea de progreso y que, de algún modo, se refleja en las estéticas del desencanto; en, como diría Groys (2005), la imposibilidad de lo nuevo. Pero no, lo nuevo sigue estando, se sigue proyectando: hay cine experimental, elementos futuristas en las pasarelas o creaciones que se alejan de lo conocido, pero no vende, no igual; no se emite en las horas de mayor audiencia, no permanece semana tras semana en las carteleras de grandes multicines, ni en escaparates de cadenas de centros comerciales, ni en la primera plana de plataformas como Netflix, youtube, Amazon o demás hornacinas del consumo de masas.

¿Qué significa esto? Como poco, que aquellas obras que miran al pasado son las que mejor están sintonizando con el sentir general y, por ello, son las que más venden, pues movilizan al público, le hacen removerse, sentir, les despiertan la necesidad de actuar, de gastar, de consumir, de hacerse con aquel producto que, por el motivo que sea —aquí lo analizaremossienten el impulso de poseer, de estar en él, de interesarse (inter-esse) por él. Y ello nos arroja a una segunda pregunta, necesaria, ¿por qué nos interesa tanto el pasado?, o, mejor dicho, ¿qué hace que nos interese tanto aquello

${ }^{5}$ A. Nieto y P. Aznar, «La nostalgia está de moda, y tiene todo el sentido (económico y emocional) del mundo", Xataka, 20/3/2017. [En línea]: https://www.xataka.com/empresasy-economia/la-nostalgia-esta-de-moda-y-tiene-todo-el-sentido-economico-y-emocional-delmundo

${ }^{6}$ Ver A. Hoeven, «Remembering the popular music of the 1990s: dance music and the cultural meanings of decade-based nostalgia», International journal ob heritage studies 20/3 (2012), pp. 316-330. 
que, por determinadas asociaciones, evoca el recuerdo de nuestro pasado? A nuestro parecer esto no responde meramente a un impulso consumista, no únicamente como veremos, tras ello hay una motivación más profunda que responde a una incomodidad con el presente, a una angustia por una sociedad que se presenta fragmentada e inhóspita para con el ciudadano. Justamente sobre ello trataremos en este artículo, sobre los motivos que nos llevan a sentir un interés casi indeleble por aquello que evoca nuestros recuerdos; sobre qué hace que nuestra sensibilidad para con la realidad en torno se haya teñido, como si vertiéramos tinta en un vaso de agua, de un tono preponderantemente nostálgico hasta atrevernos, sin pudor, a hablar de la nostalgia como el telón de fondo dominante - con permiso de la angustia- al menos en la sociedad occidental contemporánea.

\section{En circunstancias inhóspitas}

Decía Ortega que «la reabsorción de la circunstancia es el destino concreto del hombre» (OC, I, 756). Lo quiera o no, el ser humano vive en su mundo, naufragando entre sus asuntos. La realidad circundante le es inherente en tanto existe en ella, fundamentalmente ocupado con aquello que, de esta, por diversos motivos, le afecta o le reclama. De aquí que la comprensión y plena ejecución de lo que es pase, si así lo pretende, necesariamente por la comprensión de la circunstancia donde vive, su medio entorno. Es preciso emprender ese camino de comprensión en tanto estaren-el-mundo para asumir las riendas de su vida, su vida auténtica, para lo cual, como apunta Marías (1983, pp. 400-401), debe «imponer a lo real su proyecto personal, dar sentido a lo que por sí solo no lo tiene [...] convertir eso que simplemente "hay ahí en torno mío" (circunstancia) en verdadero mundo, en vida humana personal».

Cuando Ortega habla de una reabsorción de la circunstancia no alude a una mera aceptación de lo circundante, no se conforma únicamente con captar lo que hay más allá de uno mismo sino que apela a una preocupación más honda. En sus Meditaciones hablaba de la salvación $n^{7}$ para expresar precisamente la idea de la comprensión del sentido de las cosas, de lo que aún no se ve, de lo que hay de velado en cada expresión y espera ser descubierto (alétheia), salvación en tanto afán de comprensión o amor intelectual,

${ }^{7}$ Coincidimos con la noción de «salvación» que presenta Jaime de Salas como «vivir en claridad respecto a la época en la que [a cada cual] le ha tocado vivir y respecto al proyecto que ha elegido llevar a cabo en ella» (De Salas 2013, p. 231). 
que «va ligando [...] cosa a cosa y todo a nosotros, en firme estructura esencial» (OC, I, 749), esto es, que no solo se ocupa con lo que hay, sino que se detiene a comprender sus relaciones, de cosa a cosa, hasta llegar a lo que soy. Comprender lo que soy pasará siempre por la comprensión del sentido de lo que me circunda dadas las coimplicaciones que mantienen yo y circunstancia, en tanto en su coexistencia descansa aquello que constituye lo que radicalmente soy: una vida humana.

Nuestro destino, decía Ortega, es el de la luz como imperativo, "una misión de claridad sobre la tierra [...],raíz misma de su constitución» (OC, I, 788), nuestro destino es quitar el velo de la omisión, del descuido, de todo aquello en lo que naufrago y aprehenderlo cognoscitivamente, reabsorber la circunstancia, pues «solo a través de ella puedo integrarme y ser plenamente yo mismo» (OC, I, 756).La circunstancia nos es propia, nos complementa, y ello solicita cierto precepto ético para con ella; como quien cuida de sí mismo deberemos responsabilizarnos de nuestro entorno inmediato, cuidar de él. No hacerlo, y esto para Ortega era un mal terrible, conducirá a la «inconexión, que aísla y desliga, atomiza el orbe y pulveriza la individualidad» (OC, I, 749); o lo que es lo mismo, a una desadaptación de consecuencias terribles para el despliegue de nuestro proyecto de vida.

Esta reabsorción supera, entonces, el mero conocimiento del entorno implicando en sí misma cierta obligación moral para con él, cierta responsabilidad desarrollando con ella nuestro plan vocacional, al que aspiramos y que, por ello, aún no somos. A comienzos del siglo xx, esta tarea de salvar la circunstancia era consideraba propia de héroes, no de unos héroes como los que ahora vemos en las salas de cine, sino de héroes anónimos, personas de carne y hueso que, pese a los avatares que el entorno presentaba y la angustia que ello despierta, se obstinaban en ser ellos mismos, en ser auténticos luchando por lo que aún no son pero que tienden con firmeza a lo que aspiran ser, entre realidad e idealidad. La clase de héroes de la que hablamos asume que, en cada gesto, se halla una pequeña dosis de posibilidad de ajustar el mundo a un sueño, que sabe que tras las pequeñas verdades de sus ojos hay un abismo de profundidad y sienten la responsabilidad de captar la esencia eterna de las cosas justamente en las cosas mismas, descubriendo en cada mirada el eslabón que les vincula a la gran cadena del ser y, en consecuencia, la posibilidad de actuar en ella.

Pero cuando Ortega postulaba estos argumentos aún era 1914, aún; además que se dirigía a un lector muy concreto, al de una España como él la definía aislada, "restaurada», abastecedora de mediocridades y caciquismos. Impelía a asumir, mediante la aceptación de su tiempo, la inevitable necesidad 
de atender a sus circunstancias más rayanas y actuar en consecuencia, esto es, hacer comprender la necesidad de aventurarse heroicamente a la regeneración profunda de su país, de su cultura y de su mentalidad. Pese a ser una obviedad, nada tiene que ver apelar a la heroica en la España de comienzos de siglo xx que hacerlo en la de hoy día, cien años después. Mucho ha llovido desde entonces. En los comienzos del siglo xx España adolecía, sí, pero Europa, en plena Belle Époque, se ofrece como alternativa. Había oportunidad, fueron tiempos que bien podríamos referir de esperanzadores pese a que las circunstancias no fuesen precisamente facilitadoras para la mayoría de la población, ni mucho menos. A pesar de la ciertamente aciaga circunstancia que soportaban las clases bajas - mayoritarias siempre- en cuanto a explotación laboral, discriminación social, pobreza extrema, etc., los proyectos de vida del pueblo se percibían como posibles, viables en mayor o menor medida; herederos de un profundo proceso de modernización que se antojaba inagotable, los europeos vivíamos en una especie de ensueño donde la percepción de progreso era incuestionable, incluso a pesar de las quejas que aluden a una España que parecía preferir viajar en el vagón de cola, un país que tampoco era ajeno a la intensa industrialización, a las migraciones rurales, a las altas tasas de empleo en las capitales, a los pequeños logros sociales en terreno de igualdad y derechos, al mayor conocimiento de las realidades ajenas de un mundo que empezaba a volverse global... todo, todo en general conducía a pensar en un cierto grado de posibilidad, en todo caso se contemplaba luchar por sus proyectos, por regenerar esas circunstancias que para nada lo ponían fácil. No en vano, los pensamientos utópicos o determinadas ideologías, canalizadas a través de los movimientos sociales comunistas, anarquistas o fascistas, dominaban el espectro proyectivo de las personas; todo el mundo se posicionaba — aunque lo hiciesen en privado-, siempre contemplando al otro en su disposición como parte complementaria del escenario coyuntural -aunque fuese en contrariedad ${ }^{8}-$. En general, por una u otra vía, se contemplaba la posibilidad de «luchar» por un futuro «mejor» ${ }^{9}$.

${ }^{8}$ Como apunta Giner (2001, p. 359) a propósito de Simmel y el conflicto: «una de las repercusiones (...) es justamente la de fortalecer y dar un sentido a la conducta colectiva de los grupos que entran en liza (...), el conflicto confiere identidad, orientación y hasta razón de ser a las partes enfrentadas».

${ }^{9}$ No hay que esforzarse para recuperar algunas de las revoluciones que sacudieron este periodo por parte de la población civil: la de los jóvenes turcos, el alzamiento de la Pascua irlandesa, las de San Petersburgo que derivaron en el Estado Soviético, o el noviembre alemán. Incluso fenómenos que, menos agudos, no por ello resultaron menos contundentes como la germinación del nacionalsocialismo en Alemania. 
Poco más de cien años nos separan, y sin afán de resultar catastrofistas, no podemos ignorar que por el camino nos hemos encontrado con dos guerras mundiales, un holocausto y dos bombas atómicas que, en el tablero local, se bastarán con una devastadora guerra civil y una interminable dictadura. A ello podemos sumarle el desvanecimiento de las promesas sociales, como el comunismo, que se llevó consigo toda esperanza utópica; también el de una sociedad igualitaria y de oportunidades que se nos ha presentado trufada de crisis de aspecto económico y fondo social que, quizá tras un tiempo de aparente reencuentro enmascarado por la ilusión del Bienestar, nos ha dejado en la misma resaca que nos desorientase antaño. Entre tanto, los estados, sin atisbo de hegemonía, se ven abocados a pervertir el contrato social con sus ciudadanos, incapaces de controlar los excesos de globalización que trajo la injerencia de un capitalismo que los sobrepasa y los somete, estados incapaces de contrarrestar los nuevos modos de violencia, los incrementos de la desigualdad, de falta de oportunidades, de desarraigo y migración; qué decir de su posicionamiento frente a las crisis ecológicas o sanitarias que hoy asolan ya el planeta entero. El dibujo no podría ser más distinto. El número de factores de desprotección que sufre la población civil, sin el apoyo de los estados y desencantado de las ideologías, sin filiación de clase, superan en demasiado la capacidad del individuo de resarcirse y luchar su proyecto de vida, hallándose, como poco, indefensos frente a la incertidumbre. Y es que la circunstancia actual no solo se percibe hostil e insolidaria, al descontento se suma la incertidumbre por lo que vendrá, derivando en una sensación de indefensión creciente frente un futuro que no asegura en absoluto el desarrollo de un proyecto que dé sentido a su vida, en tanto solo hallamos sociedades crepusculares, fragmentadas, «descontentas de sí mismas [...] donde cada uno forma para sí proyectos y expectativas más positivas. Situación inversa de la que hemos vivido durante mucho tiempo" (Touraine 2005, p. 88).

Arrancamos, de este modo, el siglo xx con las fuerzas de quien desea cambiar el mundo para construirlo con sillares nuevos, más amable, más proyectivo; acabamos el mismo con el agotamiento de quien siente que ha fracasado en tal empeño. Quizá el mundo no sea peor de lo que era, lo que es seguro es que no es como soñamos que sería. Y la contrariedad trae consecuencias emocionales —abatimiento, decepción, desencanto-, consecuencias que no pueden más que traducirse, cuando miramos al mundo y nos vemos en él, en un estado de angustia que impregna la manera en que lo asumimos y comprendemos. Hablábamos del imperativo de reabsorber la circunstancia; ahora nos preguntamos, visto lo cual, qué sucede cuando, 
a pesar de nuestros esfuerzos, esta se niega a conciliar con nuestros planes, ¿qué sucede si una vez reabsorbida, si asumido el papel que nos exigíamos, sentimos solo decepción e incertidumbre?, ¿podría ser que en vez de ese impulso por responsabilizarnos de ella lo que sintamos sea más bien lo contrario, una tendencia a la evitación? Quizá no estemos ya tan en sintonía con el deseo orteguiano y, en vez de lucharla, lo que deseemos ahora sea justamente esa desconexión que tanto le espantaba. Quizá nuestro tiempo no esté tanto por cambiar el mundo y lo esté más por una rotura respecto de ese espacio común, abandonándolo, dejándolo a su suerte mientras buscamos amparo en otros horizontes más moldeables, menos compactos. Si el afuera nos parece irreductible, puede que el refugio solo lo encontremos adentro, en el abrigo de la intimidad, en uno mismo.

Angustiados, pues, aborreciendo (abhorrēre) el mundo que nos rodea, quizá este deje de interesarnos por estéril e incompatible, y el interés, siempre activo, busque otros nidos ${ }^{10}$. Frente a un presente doliente y un futuro incierto, nos vemos cada vez más forzados a desconectar del presente buscando efugio en el único tiempo que, por exclusión, nos queda a la mano concediéndonos cierta esperanza de familiaridad: el pasado, el pasado recordado. "A medida que las esperanzas de progreso se desvanecen, la herencia histórica nos trae el consuelo de la tradición» (Lowenthal 1997, p. 9). El pasado, en tanto recordado, es tan particular como manejable, tan propio que nadie puede arrebatárnoslo, ni prohibírnoslo, pues «las irreductibles oscuridades del pasado, la multiplicidad de interpretaciones de las que toda selección de hechos pretéritos es susceptible, y el resultante carácter incompleto y polémico [...] son precisamente las ventajas que presenta» (Bauman 2017, p. 68).

El quijotesco juego que balancea — heroicamente- entre idealidad y circunstancia se decanta a partir de este momento del lado idealista, al menos en lo referente a la trazabilidad de planes ${ }^{11}$ pues, en tanto elegimos

${ }^{10}$ Aunque por caminos diferentes y salvando los cambios producidos en los últimos cuarenta años, nos encontramos en este punto con el análisis de Michel Henry por el que una cultura decadente, en «estado de barbarie» — como bien podría ser la aquí descrita y que tildamos de inhóspita - acaba derivando en sentimientos de aburrimiento y de horror. C $f r$. M. Henry. La barbarie, Madrid, Caparrós, 2006.

${ }^{11}$ Esta ruptura solo la contemplamos en el campo de la anticipación. Por más que lo pretendamos — esta es la falla de toda pretensión utopista-, estrictamente no podemos romper con el presente. Este es el tiempo de la acción que nos permite sobrevivir, somos mundanos y generamos necesidades; solo él, por más aciago que lo percibamos, brinda dicha posibilidad. Cosa distinta es la trazabilidad de planes, en la anticipación del momento sí cabe todo, es 
mirar a otro lado, elegimos abandonar el presente en la trazabilidad para empezar a vivir exclusivamente desde nuestros planteamientos, en base a aires pretéritos, nostálgicos. Es muy difícil ser héroes ahora, en cambio es mucho más probable desistir en la idea de corregir el sistema y romper con él arraigando nuestros planes en otro suelo que nos conceda, al menos, la esperanza de la posibilidad, pues si algo tiene el pasado es que ya ha sido, y lo sabemos - $\mathrm{O}$ así elegimos creerlo, pues como veremos no siempre ha de ser así- contrastado. Optamos, pues, por dar la espalda al tipo de presente que nos ha tocado vivir, desistimos de reabsorber la circunstancia y, con ella, tomamos el compromiso -incluso político- de preocuparnos por un plan que emprender sobre un camino completamente reinventado, desde la más estricta individualidad. Ya se verá, en adelante, si tanta "creatividad» guarda intenciones o no de ser implementada en un futuro presente -que aunque parezca un contrasentido, no lo es-, o de si tiene o no visos de viabilidad, pues a veces se perece por exceso de voluntarismo. Pero esto nos mete ya en terreno utópico, lo que sería harina de otro costal.

\section{Nostalgia, algo más que un anhelo por recuperar el hogar}

Como ilustrase Svetlana Boym, referente en el estudio conceptual de lo nostálgico, el mismo término es un buen ejemplo ya de lo que pretende representar, pues este, todo y ser efectivamente un término de raíces griegas, para nada es un concepto de acuñación clásica, ni mucho menos, más bien se podría definir como un concepto nostálgicamente griego, o pseudogriego (Boym 2015, p. 25). El término, que aúna en su seno las nociones

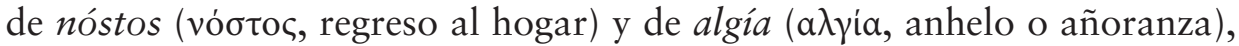
hace referencia fundamentalmente a la tristeza melancólica, esto es, vaga, profunda y permanente, que origina el recuerdo de una dicha perdida ${ }^{12}$, en

un campo virtual donde engendramos todo tipo de mundos concebibles, diferentes, quizá mejores, y orientar la acción sobre la menesterosa realidad en torno.

${ }^{12}$ El concepto fue acuñado por Hofer en su disertación de 1688 (J. Hofer, «Medical Dissertation on Nostalgia», Bulletin of the history of medicine 2 (1934), pp. 376-391) para dar nombre a una enfermedad muy extendida entre estudiantes, criados o soldados suizos que, lejos de su patria, sentían añoranza de su tierra natal. Durante los siglos XVII al XIX se consideró primero una dolencia neurológica luego psicológica, incluso estudiada en el xx por psicoanalistas como variante de la depresión, el duelo o la psicosis. Con todo, pese a que el nombre es de acuñación moderna, no lo es lo que representa. Ejemplo de ello es la Odisea de Homero, donde el nóstos es tema central; también en la Eneida de Virgilio y el posterior elenco de epopeyas que repitieron el manejo de la prospección etiológica hasta 
su generalidad una dicha relacionada con la idea de patria o del hogar que ya no existe, e incluso que nunca ha existido (Boym 2013, p. 7), y que ahora añoramos. En todo caso, más allá de cómo la llamemos e incluso antes de que la llamásemos así —no nos detendremos aquí en el análisis conceptual del término pues se ha hecho ya en otros lugares ${ }^{13}$-, este da nombre a una vivencia que sí es real, una vivencia compleja que nos interesa en tanto guar$\mathrm{da}$ afectaciones poderosas en el desarrollo de nuestros proyectos de vida.

Entrando en materia, pues, podemos apuntar que lo primero que siente la persona que atraviesa un estado nostálgico es la atracción ejercida por un recuerdo avivado que, en su presentificación (Vergegenwärtigung), provoca en ella una dicha reconfortante. Motivado por un estímulo evocador —un elemento externo o interno que, por asociación a un suceso pasado, es capaz traer el episodio a la memoria y provocar una reacción a tales efectos- el sujeto se ve arrastrado hacia un recuerdo inusualmente vívido de algo perdido, regularmente relacionado con aspectos que atañen al vínculo familiar o sentimental —relaciones afectivas que ya no están, en su mayoría propias de la infancia, y que implican a seres queridos, objetos, lugares, etc. ${ }^{14}$-. Estos recuerdos se caracterizan por ser aquellos que pretendemos mantener vinculados a lo que ahora somos, actuando explícitamente incluso para ello, en un intento de continuidad con el presente; los queremos seguir reconociendo parte de nosotros ${ }^{15}$, «alrededor de un tiempo que se imprime

el Renacimiento; también Dante en su Peregrinatio apela al anhelo por regresar; como los poetas medievales, sirva el siglo de oro valenciano como ejemplo con autores como Ausiàs March, donde ensalzaban su «enyorança». Shakespeare la retomó en su Rey Lear, y así hasta nuestros días. Cada uno con sus matices, unos atendiendo más aspectos incapacitantes, otros obsesivos, algunos motivadores, la historia evidencia precisamente la complejidad de la vivencia y el amplio abanico de atribuciones a las que se presta.

${ }^{13}$ Hemos citado a Boym, pero también podemos apelar a J. J. Scheuchzer, «De nostalgia", De Bononiensi Scientiarum et Artium Instituto atque Academia Commentarii I (1731), pp. 307-313; a J. Starobinski, «The Idea of Nostalgia», Diogenes 54 (1966), pp. 81-103; G. Rosen, «Nostalgia: A Forgotten Psychological Disorder», Clio Medica 10/1 (1975), pp. 28-51; Castelnuovo-Tedesco, P.«Reminiscence and nostalgia: The pleasure and pain of remembering», en S. I. Greenspan y G. H. Pollack (Eds.), The course of life: Psychoanalytic contributions toward understanding personality development III: Adulthood and the aging process, Washington DC, U.S. Government Printing Office, 1980, pp. 104-118.

${ }^{14}$ Así lo respaldan estudios experimentales como los de T. Wildschut, C. Sedikides y C. Routledge, "Nostalgia - from cowbells to the meaning of live», The Psycologist 21 (2008), pp. 20-23.

${ }^{15} \mathrm{La}$ discontinuidad pasado-presente, por regla general, se da relacionada con estados ansiedad (M. J. Milligan, «Displacement and identity discontinuity: The role of nostalgia in establishing new identity categories», Symbolic Interaction 26 (2003), pp. 381-403). Por su parte, la autocontinuidad se relaciona con el bienestar psicológico y la estabilidad emocional 
activamente en la construcción del yo y que continúa ejerciendo una presencia en el presente» (Trigg 2018, p. 44). Por ello, suelen ser recuerdos que, en el momento de su evocación nos despiertan alegría o ternura, pues no solo traen un contexto afectivo agradable al presente sino que suponen el reencuentro con una parte de nosotros — real o ideal— que considerábamos perdida pero que anhelamos mantener, dando con ellos muestra de la confirmación de un proyecto. Su presentificación, con ese intento de reforzar la continuidad o debilitar la discontinuidad que sentimos entre nuestro pasado y nuestro presente, es considerada como positiva por quien la vive ${ }^{16}$, de manera que dignifican el pasado que tuvimos, o querríamos haber tenido, y los vinculan a un presente más o menos incierto que intentamos redimir. Un anclaje tal con nuestro pasado, y esto fundamental, satisface la necesidad de pertenencia a algo, a una tierra, a una comunidad, a una familia; da forma a lo que somos reafirmando un proyecto frente a la incertidumbre que nos provoca el presente que avanza inquebrantable hacia un futuro tan incierto, tan angustioso, como el citado.

Por un instante, el recuerdo se presenta con una aparente capacidad de transportarnos, al menos afectivamente, al mismo momento en que se produjo el suceso originario, evocando sensaciones consideradas propias de aquel tiempo y que despiertan en nosotros una vivencia de plenitud, de ternura y gozo por la sensación de familiaridad que nos provoca. Es lo más cercano que podemos sentir al retorno de algo amado que ya no poseemos y que sabemos imposible de recuperar, pues, pese a que el recuerdo

(D. McAdams et al., «When bad things turn good and good things turn bad: Sequences of redemption and contamination in life narrative, and their relation to psychosocial adaptation in midlife adults and in students", Personality and Social Psychology Bulletin 27 (2001), pp. 472-483). Para algunos, la nostalgia actúa como respuesta a la autodiscontinuidad - siempre que no sea pretendida, no podemos sentir nostalgia de lo que no anhelamos-, en sus estudios observan cómo esta ejerce de fuente de autocontinuidad y se presenta con mayor preeminencia en quienes perciben una fuerte autodiscontinuidad (C. Sedikides et al., «Nostalgia counteracts self-discontinuity and restores self-continuity», European Journal of Social Psychology 45/1 (2015), pp. 42-61).

${ }^{16}$ Estudios de caso apuntan a que los recuerdos nostálgicos se vinculan a situaciones trascendentes o en el contexto de interacciones sociales, fundamentalmente familiares (C. Sedikides, T. Wildschut y D. Baden. «Nostalgia: Conceptual issues and existential functions», en J. Greenberg, S. Koole y T. Pyszczynski (Eds.), Handbook of experimental existential psychology, Nueva York, Guilford, 2004, pp. 200-214). Estudios posteriores refuerzan cómo en el recuerdo se tiende a enfatizar más el aspecto positivo que el negativo (S. L. Holak y W. J. Havlena, «Feelings, fantasies, and memories: An examination of the emotional components of nostalgia", Journal of Business Research 42 (1998), pp. 217-226) así como se observa una acción redentora donde recuerdos positivos anulan eventos negativos (D. McAdams, «The psychology of life stories», Review of General Psychology 5 (2001), pp. 100-122). 
pretende justamente esto, tender a cierta renovación de la percepción originaria, somos conscientes de que este nunca nos la podrá ofrecer sino solamente como una copia inexacta de ella; el recuerdo (Andenken) no es más que una otra-vez, una vivencia que se presenta cuasi-originariamente ${ }^{17}$ aunque siempre como «una alteridad que trasciende la conciencia presente» (Ferrer 2011, p. 172), pues en todo momento se sabe pasada. Pese a su carácter de presencia de la cosa ausente (Ricœur 2003), el recuerdo no llega a confundirse nunca con la percepción actual, ni con una fantasía carente de posicionamiento. Sabemos de la distancia —el olvido juega un papel importante- que separa el momento recordado del actual, no perdemos consciencia de nuestra posición en un emplazamiento respecto del ahora y de la esfera del campo temporal originario del recuerdo, como tampoco de la irreversibilidad que le es propia, pues el recuerdo siempre se da como un haber-sido percibido. Pero, pese a su inautenticidad, la seducción que provoca fuerza a aferrarnos a él, el deseo por reabrirlo resulta poderoso, de aquí la paradoja en la que nace la nostalgia.

El recuerdo, aunque en algún momento Husserl lo llegase a definir como un «apagamiento del presente» ${ }^{18}$, no es una mirada fija hacia el pasado que sencillamente se desvanezca, cierto que es una vivencia que progresivamente se hunde en la oscuridad de la memoria, que se debilita y pierde claridad pero, como también analizó, este subsiste en cada presentificación, recuerdo tras recuerdo, a la vez que muda. La percepción originaria queda irremisible en el pasado, en cambio la consciencia originaria «es un acto que constantemente declina o se gradúa» (Husserl 2002, p. 68) en una corriente que se actualiza a cada mirada, eso sí, expuesta a intenciones de expectativa que impulsan el recuerdo hacia una vivencia renovada en cada dación. Cada vez que se actualiza la actividad perceptiva pasada, en muchas ocasiones ya modificada por presentificaciones previas, esta cambia en tanto «cada novedad reobra sobre lo viejo, cumple su intención prospectiva y con ello la determina» (Íbid., p. 75) exponiéndola a una modificación continuada, alteraciones que se acumulan en el recuerdo como un peso a cargar y que, por su efecto, provocan que lo verdadero de la impresión originaria quede cada vez más atrás ${ }^{19}$. Es el precio de recordar: recuperar solo aproximaciones de

${ }^{17}$ Hua XXXIII, 364, 7-9 (Die Bernauer Manuskripte über das Zeitbewusstsein, en Bernet, R y D. Lohmar (Eds.), Dordrecht/Boston/Londres, Kluwer Academic P., 2001).

${ }^{18}$ Íbid., 65, 14-18.

19 Íbid., 379. Enlaza la idea con el concepto heideggeriano del Andenken. Para este, el recuerdo implica una destrucción, una distorsión, también un incorporar al pasado que desemboca en su transformación. 
la percepción originaria, cada vez más desvirtuadas; a la par que exponer el recuerdo a una fragmentación de apariencias imaginarias que dejan tras de sí un margen de oscuridad, generalidad, oscilación e incoherencia respecto del pasado al cual, sin embargo, se mantienen relacionadas ( $c f r$. Ferrer 2011, p. 180).

Pero la rememoración solo es el desencadenante de un proceso que aún se presenta más complejo. Para que se produzca el sentir nostálgico, ese estado de tristeza melancólica, la dicha recuperada debe antes desaparecer y tornarse duelo. La dicha que hallamos en el recuerdo se desvanece tan pronto interceden nuestras expectativas y tomamos consciencia de nosotros mismos. Lo evocado no es una mera fantasía, es algo que considero parte de mí y que se incrusta en mi flujo de consciencia como una experiencia propia que une el pasado al presente que nunca he abandonado ${ }^{20}$. Esto provoca un quebrantamiento del contexto afectivo en el que nos encontrábamos arrojados. Si en un inicio la evocación me trajo la dicha en un entorno de familiaridad, con la irrupción de las expectativas y de mí mismo llega el presente. La dicha que sentíamos comienza a disiparse dejándonos el recuerdo del recuerdo, o mejor una retención de la vivencia del recuerdo que, con todo, confirma una pérdida anunciada. Es la evidencia de la simulación, de que navegábamos en una otra-vez que ahora se torna más otra, de su finitud, de la imposibilidad de redención de algo que, efectivamente, es pasado e irrecuperable. Esto nos conduce a un nuevo momento en la vivencia nostálgica — si aceptamos la artificialidad de dividir un flujo natural-, cuando la dicha empieza a desvanecerse o se pone en cuestión su continuidad provocando en nosotros un estado doloroso, de duelo por aquello que, una vez más, empieza a perderse y que tan bien nos había hecho sentir.

La pérdida de dicha genera un desconsuelo doblemente inducido: por el reconocimiento resignado de que deseamos un suceso irrecuperable —que avivará un anhelo por el pasado-; y por la pérdida misma del balsámico contexto afectivo en el que nos hallábamos sumidos tras su recuerdo - que puede motivar una voluntad de permanecer en él一. Aunque el dolor por el duelo se origina en el momento en que asumimos la imposibilidad inherente del recuerdo, lo que, como decimos, genera un fuerte anhelo, este no

${ }^{20}$ Advierte Husserl cómo en cada evocación debemos distinguir la reproducción de la consciencia en que se dio el objeto duradero pasado y lo que se vincula a esta reproducción como constitutivo de la conciencia "pasado" o "presente" o "futuro"... reproduciendo todo, no solo la conciencia de objeto, sino la corriente de conciencia hasta el presente vivo. Cfr. E. Husserl, Lecciones de fenomenología de la conciencia interna del tiempo, Madrid, Trotta, 2002, p. 75. 
desplaza el estado dichoso que la vivencia rememorativa ha causado, al menos no de una vez, en tanto temple (Stimmung) ${ }^{21}$ su contexto afectivo permanece, la vivencia se mantiene asida quedando en nosotros su efecto, impregnando el presente con su halo de dicha ${ }^{22}$. Tras la experiencia rememorarte, el efecto de esta como acto se va oscureciendo, pero el estado de dicha que de él se desprende perdura como un fondo anímico que, poco a poco, va mezclándose con el regusto doloroso de saber de la imposibilidad a la que aspiramos, de aquí que nos aferremos a la vivencia dichosa, esforzándonos por regodearnos en ella, si fuese preciso, actuando para ello. Esto es la nostalgia en sentido estricto, el anhelo ${ }^{23}$ por recuperar el contexto afectivo que el pasado - ahora presentificado- le ha concedido y que no consigue conservar, un anhelo que no se refiere tanto, pues, a un objeto - pues no tiene referencia intencional explícita a ninguno- sino a la incitación misma del estado afectivo que ha provocado la rememoración y que, como una coloración de duración indeterminada, sigue manteniéndose como conciencia de fondo desde o sobre la que actuaremos (Hua XXXVIII, 176-177).

El anhelo en sí mismo, en tanto tendencia afectiva, no posee voluntad de acción, al contrario, solo aspira regresar a algo que sabe irrealizable, pero en su tendencia fundamenta una voluntad - pues no son vivencias aisladas ${ }^{24}$ - la cual pretende protegernos del elemento de duelo, esto es,

${ }^{21}$ Sobre el concepto de temple anímico en Husserl ver: Hua XXXVIII (Wabrnehmung und Aufmerksamkeit. Texte aus dem Nachlass, en Vongehr, T y R. Giuliani (Eds.), Dordrecht, Springer, 2004); también la V (\$15b) de sus Investigaciones lógicas; y Estudios acerca de la estructura de la conciencia, que aún se hallan inéditas, por lo que remitimos a A. Zirión Quijano, "Coloraciones emotivas y temples anímicos en los Estudios acerca de la estructura de la conciencia de Husserl», Isegoría 60 (2019), pp. 123-145.

22 «Las sensaciones [...] pueden perdurar, mientras que desaparecen los caracteres de acto edificados sobre ellas. Cundo los hechos suscitadores del placer han pasado a un segundo término, cuando ya no son apercibidos afectivamente, e incluso quizá cuando ya no son objetos intencionales, la excitación placentera puede durar todavía largo tiempo». E. Husserl, Investigaciones lógicas 2, Madrid, Alianza, 2014, $\$ 15$ b, p. 510.

${ }^{23}$ En la nostalgia el deseo no se torna querer. El querer entraña en sí una voluntad de tender hacia lo que se quiere, lo que indica que quiere algo que está por venir, que aún no se posee pero que se reconoce como posible. En el temple nostálgico, empero, lo que se desea se sabe irrecuperable, pues se desea volver a vivir lo vivido y lo vivido ya no volverá, es vivencia pasada que, a su vez, evoca a otras anteriores en un continuo de recuerdos-expectativas que se remontan hasta la impresión original, todas ellas perdidas en tanto actos, confinadas en escorzo en el recuerdo último aún por venir que, como en las anteriores, será una nueva vivencia distinta de todas las demás. Por ello no decimos que queremos el pasado, sino que lo anhelamos, pues lo sabemos imposible.

${ }^{24}$ «Si bien el anhelo y la voluntad no son lo mismo, ambos pueden coexistir sin contradicción en una situación. La nostalgia parece ser un caso donde hay voluntad y anhelo de 
perseverar donde nos encontramos, mantenernos en el estado actual que nos permite regodearnos en el remanente de la dicha que resta tras la vivencia rememorativa - por ejemplo mediante el acopio de estímulos evocadores que permitan el recuerdo a cada momento: fotografías, cine, ropa...la sociedad de consumo es un claro ejemplo- El anhelo, como la voluntad de permanecer, son dos respuestas relacionadas aunque independientes que pueden emerger frente al dolor/angustia que queda con el oscurecimiento paulatino de la dicha. Esta dualidad puede dar razón a que la nostalgia se exprese en algunos como incapacitante y deshacedora de voluntad y en otros, en cambio, actúe como fuerza motivadora, así como de que los estudiosos se debatan constantemente en si considerarla una disposición del ánimo o un elemento motivador, cuando a buen recaudo, ambas cualidades forman parte de ella.

Con todo, podemos concluir aseverando a la nostalgia como un temple afectivo donde se combinan al tiempo una tristeza melancólica causada por el anhelo de algo que se sabe imposible — un pasado irrecuperable-, aderezado con los restos de una dicha en forma de consuelo que, en pos de su conservación, tiende a activar una voluntad dirigida a permanecer en ese estado pretendido de complacencia y familiaridad, que nos hace sentir como estando-en-casa (heimlich ${ }^{25}$.

\section{Angustia y nostalgia, recuperar el hogar sin perderse a sí mismo}

Retomando el escenario circunstancial antes descrito y si, tras el paréntesis analítico sobre la nostalgia, tuviésemos que adjetivar la circunstancia actual con un solo término, sin duda elegiríamos el de inhóspita. Más allá de las comodidades y privilegios que sin duda este tiempo alberga respecto de épocas anteriores, la incertidumbre y el desencanto, el aislamiento por desamparo, por falta de arraigo y filiación que hemos citado desemboca en una terrible pérdida de familiaridad respecto de nuestro entorno más cercano,

manera simultánea en una misma vivencia compleja, apuntando cada uno a diferentes objetos». I. Quepons, «Nostalgia y anhelo. Contribución a su esclarecimiento fenomenológico», Open Insight 4/5 (2013), p. 139.

${ }^{25}$ La idea del hogar, de casa, relacionada con un estado de familiaridad, de confort, de bienestar psicológico es clave para comprender la nostalgia; hogar bien en sentido físico (una casa, un pueblo) como temporal (una época, un episodio) y que se expresa a través del sistema de relaciones, con la familia, con el pueblo. A su vez, el hogar representa también esa atmósfera vivida que nos hace sentir un halo de continuidad, de unidad, de dicha. 
llevándonos a sentirnos fuera de casa, en terreno inhóspito, estando incluso en casa, lo que nos expone al dominio de un estado angustioso. Y es que, como diría Heidegger $(2009$, p. 207), en la angustia le va a uno inhóspitamente (Unheimlichkeit), uno se siente desazonado ${ }^{26}$.

Ordinariamente, nuestra relación con la circunstancia tiende a ser de ocupación para con las cosas que en ella encontramos, vivimos en el mundo atareados de un modo cuidadoso - atento-, pendientes de nuestros quehaceres o, como diría Ortega, naufragando entre nuestros asuntos. Mientras mi actitud es ejecutiva, esto es, hallo en el mundo aquello que necesito para desarrollar mis planes, este se me presenta como un todo relacional, donde todo se meda ligado y estructurado de una manera intersubjetiva; un mundo donde las cosas tienen su lugar y desde el cual estoy listo para hacer uso de ellas ( $c f r$. Trigg 2018, p. 48). Sencillamente cuento con ellas en tanto me acompañan en lo que considero un entorno de familiaridad - como en un estar-en-casa (Zuhause-sein)—. De este modo, mi vivir, tras mi atención, tenderá hacia aquello que, a la mano, se me ofrece como instrumento para el desarrollo de cual sea mi proyecto. Al menos mientras este curse según las expectativas que dicha familiaridad me presta.

La cosa cambia cuando algo altera mi ejecutividad, cuando algo no surge tal y como esperamos que surja y se da el fallo, esto es, cuando mi ocupación se interrumpe por quiebra o falta de cumplimiento, lo que en el tipo de sociedad descrita puede llegar a ser la tónica dominante. El fallo conduce a que nuestra atención quede alterada y mude de la ocupación — donde las cosas son consideradas instrumentos, a la mano- a la cosa en tanto objeto -donde se me dan estando ante los ojos-. Necesito cuestionarme lo sucedido, objetivar el momento, tomar consciencia de qué ha ocurrido y de dónde se halla el fallo. Así, no podemos más que reparar en la cosa o suceso y, con ella, por su condición relacional, en el mundo que la acoge y en mí mismo como parte del contexto - ligando cosa a cosa y todo a nosotros, en firme estructura esencial-. El fallo genera un doble efecto, por un lado que tomemos consciencia del mundo en torno: este se ilumina, «aparece el contorno, los cursos de acción, el contexto de remisiones» (San Martín 2015, p. 339), y descubro un mundo conformado de referencias en cuya

${ }^{26}$ Unheimlichkeit etimológicamente está relacionado con la idea de no tener hogar. Como apunta Rivera, "lo terrible de la angustia es que está como fuera de todo lugar, no tiene morada, no tiene dónde estar», de aquí que Gaos la tradujese como inhóspito, fuera del hogar. Rivera, en cambio, prefiere desazón, fuera de sazón, del momento justo, de su tiempo. Ambos casos apelan a la sensación de pérdida de familiaridad. En M. Heidegger, Ser y tiempo, Madrid, Trotta, 2009. 
familiaridad nos movíamos y que, en tanto lo atiendo, evidencia que se hallaba ya ante mí previo a mi mirada, de antemano. El segundo efecto es que en esa rotura con el mundo, en esta alteración de mi ejecutividad, pierdo mis referencias, repentinamente dejo de estar-en-casa, «la familiaridad cotidiana se derrumba» y paso de estar arrojado al mundo que me tenía absorto a quedar "aislado, pero aislado en cuanto estar-en-el-mundo" (Heidegger 2009, p. 207). De repente me hallo a mí mismo preocupado y desocupado frente a la totalidad del mundo. Es entonces cuando puedo llegar a sentir la desazón que trae la angustia coloreando la atmosfera con su tono emocional, es la angustia del mundo. «Aquello ante lo cual la angustia se angustia es el estar-en-el-mundo mismo» (Heidegger 2009, p. 205) como algo inesperado, extraño, frente a uno mismo como posibilidad de ser desde sí mismo, para elegir y elegirse, jugándose la autenticidad de la propia existencia.

Así, esta extrañeza, eso inesperado, genera desazón, nos hace sentir mal como no-estando-en-casa (Un-zuhause), donde ya no podemos dar nada por sentado en tanto no hay conocimiento implícito de cómo funciona lo que nos resulta extraño o ajeno. La angustia rompe con la familiaridad, provocando un quebrantamiento de la cotidianidad, exponiéndonos al vacío, a la nada que supone hallarse a sí mismo estando en el mundo sin ocupación, no hay un ente al que temer, solo la nada. El Dasein se angustia al reparar en su soledad como estar-en-el-mundo y siente angustia ante sí mismo, ahora debe elegir qué hacer - o quehacer-, pues se enfrenta a la ausencia de relaciones, a la nada.

La angustia rompe con la temporalidad de la individualidad que defendíamos como continuidad consigo mismo y que contribuía a esa idea de hogar. Previo al fallo, ocupados, nos hallábamos en casa, vivíamos bajo la coloración de un temple que cosía de coherencia nuestras acciones, tras el fallo, este se ve conquistado por otro que impone su propio tono, muy distinto al anterior, incapaz de conciliar con él, por lo que convierte el mundo en un lugar de silencios, donde las cosas pierden su nombre y sus relaciones, tornándose anónimas e inconexas. Por ello decimos que «la angustia le quita al Dasein la posibilidad de comprenderse a sí mismo en forma cadente a partir del "mundo" y a partir del estado interpretativo público" (Íbid., p. 203), pues lo aísla en sí mismo, como estar-en-el-mundo.

Pero «solo en la medida en que el Dasein es llevado por esencia ontológicamente ante sí mismo por su propia aperturidad, puede también huir ante sí mismo» (Íbid.). Esta, motivada por la misma angustia, se traduce en una tendencia a la caída, a regresar a las ocupaciones con la intención de 
ignorar la propia presencia, llevando su atención nuevamente a naufragar entre esos asuntos en los que se hallaba más seguro, en un entorno de familiaridad, de costumbres... cosa distinta es, si en ese tránsito, en ese "retorno", el sujeto mantiene o no la referencia a sí mismo, si se vuelve a ser «uno» desestimándose a sí mismo o se vuelve incorporando ese descubrimiento en el proyecto, «queda abierta la pregunta por la oscilación existencial entre la seguridad óntica y la inseguridad ontológica» (Baquedano 2013, 22). Más allá de cada cual, lo que tenemos por cierto es que circunstancias como la descrita más bien parecen condenas y, por más deseo de regresar a la familiaridad que tengamos, estas se empeñan a negárnosla. Retornamos, pues, a nuestra pregunta inicial: ¿qué ocurre si el escenario donde vivimos incumple sistemáticamente nuestras expectativas, si se dan como un continuo de fallos sobre fallos que imposibilitan nuestra absorción en la ocupación? Fue el fallo quien nos trajo a nosotros mismos, a la angustia de la que ahora queremos salir, pero en nuestra huida caemos de nuevo en un entorno que, por aburrimiento o aborrecimiento, nos empuja una y otra vez a la frustración de nuestras expectativas, igual de inhóspito, provocando continuos accesos de preocupación, sin posibilidad de retomar el desarrollo de nuestros proyectos de vida.

Es la nostalgia, a través de la instrumentalización del pasado, quien se nos ofrece entonces como un temple lo suficientemente evocador y evocable como para representar un efugio al dominio de la angustia en ese escenario de imposibilidad ejecutiva.

Por un lado, salir de la angustia por la puerta de la nostalgia quizá sea la tendencia más «natural» que podamos hallar, ya que frente a un presente angustioso lo que deseamos es regresar al momento previo al fallo, donde todo tenía su nombre, donde todo cumplía su función, volver a casa aun a expensas de perder cierto grado de autenticad en ello. El anhelo busca recobrar/mantener esa atmosfera de unidad donde las relaciones temporales quedan recompuestas, intentando - como indican estudios de caso (Mills y Coleman 1994)— volver a tejer los hilos rotos de la historia. Así, cualquier estímulo evocador servirá para embarcarnos en una deriva ya definida que puede llegar a enmascarar la angustia mediante la evocación de un temple distinto, más dichoso, hasta el punto, quizá, de hacer que la olvidemos. Esa sería al menos la pretensión de aquellos que prefieren seguir viviendo con las cortinas corridas, hasta el punto de convertir el deseo de familiaridad en un imperativo a preservar, una decisión legítima que renuncia a lidiar con la idea de finitud, consigo mismo y con la angustia que les va asociada. Tristemente el deseo de darle la espalda al presente - angustioso o nomediante una tendencia a la rememoración, ni elimina el presente ni recupera el 
pasado, solo desatiende determinados elementos del horizonte de consciencia con la intención de centrarse en aquello que evoca el recuerdo, que no es menos presente que esos elementos que pretende ignorar, por lo que hasta cierto punto resulta una tarea infértil, ya que el presente resulta inevitable y, con él, la exposición a la finitud y a la angustia que desea eliminar. Pero al menos ofrece un refugio temporal que da descanso mediante la ocupación - aunque sea únicamente en buscar salida ${ }^{27}$ - un descanso frente a la exigencia que la angustia impone con la elección fundamental de la propiedad o impropiedad de su ser.

Pero ya hemos apuntado como la nostalgia no es solo una reacción, también es evocable y se puede utilizar intencionadamente de cara a asumir el presente inevitable, esto es, no eliminando la angustia, pues la asume irremediable, sino manteniéndola debilitada mediante la prevalencia de otro temple, evocado, que ocupe su lugar en base a continuas presentificaciones. En un contexto que resulta inhóspito, los elementos evocadores son, de todo lo presente, lo único que me permite una salida tal a la angustia, elegirlos de manera sistemática puede ser una forma estratégica de actuar en tanto el resto de elementos circunstanciales resultan estériles para abandonarla, pues nos devuelven una y otra vez al estado del que deseo salir.

Más allá de que elijamos querer creer o no en la posibilidad de recuperar el pasado per se, esto es, de restaurar las condiciones del pasado para devolverlo en una especie de voluntarismo retrógrado - que en todo caso sigue fijándose en el presente-, el nostálgico que no pierde intencionadamente su capacidad crítica, de reflexión ${ }^{28}$, sabe que esta se basa en la evocación de un recuerdo en y desde el presente, es consciente de la finitud que le acompaña -inspirarse en recuerdos implica ya la asunción de la finitud y contextualización que les es propia-. El nostálgico sabe que necesita del vestigio o del estímulo evocador - presente- para elaborar su narrativa y perpetuar el temple deseado — también presente-; el nostálgico no ignora la irrecuperabilidad de la impresión originaria - finita - ni que su anhelo es una tendencia presente que desea algo ya desaparecido, de otro modo hablaríamos

${ }^{27}$ Estrictamente, la ocupación de buscar el pasado en el presente sería una tarea sin fin, pues el pasado se desvanece a cada evocación volviendo a comenzar la búsqueda, siempre estando en camino. En tal caso, si esta transición de la angustia a la nostalgia permitiese recobrar una familiaridad perdida en un supuesto presente de ocupaciones funcionales, la ocupación presente supondría por sí misma el fin de la nostalgia dando comienzo a un nuevo temple que, a su vez, quedaría abierto al fallo, y a la angustia.

${ }^{28}$ Boym (2015), acorde con este punto, diferenciaba entre nostalgia restaurativa y nostalgia reflexiva. 
de un querer, no de anhelar. El nostálgico que no renuncia a sí mismo y a su situación cuando "huye» de la angustia, no puede evitar asumir su presente y ocuparse de él como parte de su horizonte de temporalidad, de aquí que defendamos la nostalgia también como «fuerza dinámica y motivadora que permite al individuo mirar hacia adelante y tomar medidas proactivas» (Sedikides y Wildschut 2016, p. 319), pues engendra acciones conscientes y voluntarias, prospectivas, que no solo conectan pasado y presente, sino que pretenden el futuro con gestos que cubren desde el acopio o selección de estímulos evocadores hasta la acción social que intenta restaurar sistemas, de inspiración pretérita, que suplanten el actual. Aunque deteste el presente, el nostálgico se debe a él para salir de él, para ligar como pretende pasado y futuro en un intento de continuidad.

Hay también que remarcar que si bien el sujeto busca en la nostalgia un cambio de temple frente al angustioso, esto no significa que con él se pierda la conciencia de sí ni de su finitud, al contrario, el mero hecho de fusionar horizontes (pasado-presente) implica tener consciencia de la propia historicidad y de la finitud que le es propia, por lo que en el cambio de temple hay una mudanza de acentos, pero no un olvido ni un cambio de lugar. El cambio de temple ciertamente hace que veamos las cosas de otro modo; con la nueva coloración resaltarán diferentes figuras en el horizonte, se oscurecerán otras, pero el horizonte sigue siendo el mismo, fusionado. Salvo en sucesos traumáticos, que nos adentrarán en el campo de la anomalía, el continuum del horizonte temporal no se rompe, solo cambia de tono. No podemos inferir que, por un simple cambio de afecto, el sujeto renuncia a hacerse cargo de sí mismo, ni que el cambio de afecto se produce como consecuencia de haber renunciado a ello, pues seguimos en un modo intencional de evocación, no en una reacción de huida, lo único es que lo hacemos no mirando al presente sino al pasado evocado en el presente. Que miremos hacia otros elementos no es óbice de que se ignoren los descubrimientos precedentes ni de que cambie la intención del sujeto, entre ellos ese sí mismo como estar-en-el-mundo y la asunción de su proyecto de vida.

Nostálgico o no, sigo contando conmigo sabiendo que lo hago y en qué términos, pues desde mi descubrimiento y mientras no elija ignorarlo, soy lo que queda, aunque sea a modo de recuerdo de lo que descubrí, aún presente en la hondura de mis gestos, como una huella, como el creador y protagonista de la narración en la que decido actuar. Con la nostalgia no renuncio a mi proyecto, al contrario, seguramente que acuda al pasado con la esperanza de salvarlo, de desempolvar mis viejas promesas; tampoco con la nostalgia salgo de mí, pues los recuerdos me pertenecen, son míos, 
forman parte de mi historia, de mi pasado - incluso cuando beben de un pasado colectivo pasan por el tamiz de mi interpretación personal, como parte constitutiva del Dasein-, de ese mí mismo que hallo tras el fallo pues en tanto ser finito, el Dasein «está siempre en relación con el pasado, como aspecto de su temporalidad e historicidad, un pasado que ha de rememorar e interpretar, pues el mismo ser-ahí proviene de ese pasado y es parte constitutiva de su existencia» (González-Valerio 2003, p. 91). Cierto que mi presencia se atenuará respecto del estado angustioso, donde quedo expuesto de forma radical, desocupado y solo frente a mí como estar-en-el-mundo, y cierto que justamente la narración que posibilita el nexo del pasado con el presente provoca esto, una pérdida de autenticidad en tanto se somete a la copia de la copia, recuerdo tras recuerdo; incluso asumimos que mis descubrimientos, en tanto pretendo recuperar un clima de familiaridad, perderán intensidad en la claridad, dándoseme a media luz -y es que en ningún momento defendemos la nostalgia como el mejor de los temples para aquello de la luz como imperativo, para una luz del mediodía-, pero ello no significa que renunciemos de parte a parte a lo que soy y a mi proyecto por el mero hecho de buscar en el pasado, al contrario, en tanto estrictamente no hay retorno, no cabe huida en el pasado, solo hacia una estancia anexa de mí mismo que me ofrece amplitud para sortear las dificultades sin perder el $\operatorname{sitio}^{29}$.

\section{Conclusión}

El recuerdo del que depende el estado nostálgico mantiene cierta similitud con la obra de arte que revisaba Vattimo (2015) a partir de Heidegger. Como el nostálgico, el artista pretende fundar posibles mundos alternativos al existente — un pasado que reemplace el presente- pero, como le sucede a la poesía, el pasado se quebranta en el momento en que se dice, en cuanto se hace presente y se convierte en vivencia actual. Como el poema, el recuerdo mantiene cierto carácter monumental. No decimos con ello que toda vivencia se construya con la intencionalidad de perdurar en la memoria, pero es cierto que determinados sucesos o impresiones originales se establecen en la corriente de consciencia como si de monumentos se tratase pues, como estos, duran en la forma de una máscara fúnebre, signada, como indica Vattimo $(2015$, p. 69), por su destino de alienación radical, por la

${ }^{29}$ De aquí que utilicemos el término «efugio» y no el de huida, más relacionado con apartarse o alejarse. Efugio apela a una evasión o recurso para sortear la dificultad, esto es, a eludirla con arte o astucia. 
mortalidad. El recuerdo, en tanto rememoración de una impresión original, se construye para que esta dure en el tiempo, para mantener vivo un suceso o impresión del pasado, pero no es lo que dura, es lo que queda - y «lo que queda lo fundan los poetas ${ }^{30}$ - No dura la impresión originaria, que se pierde desde el momento en que se apaga, el sujeto no dispone jamás de su objeto, en cambio queda una copia en forma de recuerdo, y una copia de la copia, que se van alejando del original a merced de los avatares del tiempo y de las expectativas en un juego de transformación-distorsión (Verwindung); como los vestigios que hallamos en el campo, arruinados por las inclemencias y, como no, por el paso del tiempo que exhiben en ellas la finitud del monumento que eran y simbolizan. En ambos casos, tanto el vestigio como el estímulo evocador —en tanto huellas- ponen en marcha la narrativa, ese proceso interpretativo por el que reconstruir/evocar una historia a partir de ellos, pero su verdad ya no será una verdad de claridad meridiana, será una verdad que se nos da a media luz, basado en la copia de la copia de un original que va perdiendo autenticidad a cada aparición, pues ya no se dará en un momento de plenitud lumínica sino en un presente donde todo acaece, dándose en un juego de ocultamientos/descubrimientos, «la verdad como evento: el determinarse cada vez, diverso y diferente» (Íbid., p. 70), a cada recuerdo, a cada presentificación, buscando el relato de una continuidad que lo mantenga vivo hasta el presente, a pesar de darse de un modo distinto en cada ocasión. No perdemos la conciencia de su finitud, la vemos y se nos recuerda en cada expresión; no perdemos la conciencia de nosotros mismos, pues son nuestros recuerdos, nuestras promesas... la nostalgia solo amortigua la angustia que ello nos provoca exponiéndonos a una luz, mortecina, que podemos asumir y que se ajusta más a la necesidad de nuestros tiempos, pues la luz intensa del mediodía quemaría nuestra voluntad hundiéndonos, entonces sí, en la caída constante.

Afirmamos, pues, con rotundidad que la nostalgia no es el mejor temple para ese postulado orteguiano de la luz como imperativo si se pretende con una luz intensa, pero quizá sí lo sea para asumirlo mediante una luz más débil, con sus sombras o, como diría Zambrano, revestida de matices, pues no hay mejor condición para acceder a ella que en «la penumbra tocada de alegría» (Zambrano 1989, p. 10), y qué mejor temple que la nostalgia para ello, un espacio a media luz, anhelante, que despierta alguna perla de dicha en quien consigue vivirlo; quizá la luz que necesitamos hoy en día para acercarnos a la verdad.

${ }^{30}$ Aludimos con Vattimo al dístico de Hölderlin, del poema Andenken, que Heidegger solía usar: Was bleibet aber Stiften die Dichter. 


\section{Bibliografía}

Baquedano, S. «La huida ante el sí mismo: ¿seguridad óntica o inseguridad ontológica?», Tópicos 25 (2013), pp. 5-22.

Bauman, Z. Retrotopía, Barcelona, Paidós, 2017.

Boym, S. El futuro de la nostalgia, Madrid, Antonio Machado libros, 2015.

Boym, S. "Nostalgia and its discontents", The Hedgehog review (2017), pp. 7-18.

Brown, S. «Retro-marketing: yesterday's tomorrows, today!», Marketing intelligence \& planning 17/7 (1999), pp. 363-376.

Castelnuovo-Tedesco, P. «Reminiscence and nostalgia: The pleasure and pain of remembering», en S. I. Greenspan y G. H. Pollack (Eds.), The course of life: Psychoanalytic contributions toward understanding personality development III: Adulthood and the aging process, Washington, DC, U.S. Government Printing Office, 1980, pp. 104-118.

De Salas, J. «Perspectiva y el método de salvación en Ortega», en J. Zamora Bonilla (Ed.), Guía Comares de Ortega y Gasset, Granada, Comares, 2013, pp. 231-249.

Ferrer, G. «Experiencia del pasado e imágenes poéticas. Edmund Husserl y Paul Celan (una lectura fenomenológica de Sprachgitter)", Inv. fenomenológicas 8 (2011), pp. 169-204.

Giner, S. Teoría sociológica clásica, Barcelona, Ariel, 2001.

González-Valerio, M. A. «Rememoración y tradición: la hermenéutica entre Heidegger i Gadamer», Signos filosóficos 10(2003), pp. 87-102.

Groys, B. Sobre lo nuevo: ensayo de una economía cultural, València, Pretextos, 2005.

Havlena, W. J. y S. L. Holak, «The good old days: observations on nostalgia and its role in consumer behaviour», en Holman R. H. y R. Solomon (Eds.), Advances in consumer research, Provo, UT, association for consumer research, 1991, pp. 323-329

Heidegger, M. Ser y tiempo, Madrid, Trotta, 2009.

Henry, M. La barbarie, Madrid, Caparrós, 2006.

Hoeven, A. "Remembering the popular music of the 1990s: dance music and the cultural meanings of decade-based nostalgia», International journal ob heritage studies 20/3 (2012), pp. 316-330.

Hofer, J. «Medical Dissertation on Nostalgia», Bulletin of the history of medicine 2 (1934), pp. 376-391.

Holak, S. L. y W. J. Havlena, «Feelings, fantasies, and memories: An examination of the emotional components of nostalgia», J. of Business Research 42 (1998), pp. 217-226. 
Husserl, E. Die Bernauer Manuskripte über das Zeitbewusstsein, en Bernet, R y D. Lohmar (Eds.), Dordrecht/Boston/Londres, Kluwer Academic P., 2001 (Hua XXXIII).

Husserl, E. Lecciones de fenomenología de la conciencia interna del tiempo, Madrid, Trotta, 2002.

Husserl, E. Wahrnehmung und Aufmerksamkeit. Texte aus dem Nachlass, en Vongehr, T y R. Giuliani (Eds.), Dordrecht, Springer, 2004 (Hua XXXVIII).

Husserl, E. Investigaciones lógicas 2, Madrid, Alianza, 2014.

Lowenthal, D. The heritage crusade and the spoils of history, Londres, Viking, 1997.

McAdams, D. "The psychology of life stories», Review of General Psychology 5 (2001), pp. 100-122.

McAdams, D., Reynolds, J., Lewis, M., Patten, A. H. y P. J. Bowman, "When bad things turn good and good things turn bad: Sequences of redemption and contamination in life narrative, and their relation to psychosocial adaptation in midlife adults and in students", Personality and Social Psychology Bulletin 27 (2001), pp. 472-483.

Marías, J. Ortega I: Circunstancia y vocación, Madrid, Alianza, 1983.

Milligan, M. J. «Displacement and identity discontinuity: The role of nostalgia in establishing new identity categories», Symbolic Interaction 26 (2003), pp. 381-403.

Mills, M. A. y P. G. Coleman. "Nostalgic memories in dementia. A case study», The international journal of aging and human development 38/3 (1994), pp. 203-219.

Muehling D. D. «The relative influence of advertising-evoked personal and historical nostalgic thoughts on consumer's Brand attitudes», Journal of marketing communications 19/2 (2011), pp. 98-113.

Nieto A. y P. Aznar, «La nostalgia está de moda, y tiene todo el sentido (económico y emocional) del mundo», Xataka, 20/3/2017. [En línea]: https://www.xataka.com/empresas-y-economia/la-nostalgia-esta-de-moda-y-tiene-todo-el-sentido-economico-y-emocional-del-mundo

Ortega y Gasset, J. Obras completes, Madrid, Taurus: FOG, CEO, 2004-2010.

Orth, U. R. y A Bourrain. «The influence of nostalgic memories on consumer exploratory tendences: Echoes from scents past», Journal of retailing and consumer services 15/4 (2008), pp. 277-287.

Quepons, I. «Nostalgia y anhelo. Contribución a su esclarecimiento fenomenológico», Open Insight 4/5 (2013), pp. 117-145.

Ricœur, P. La memoria, la historia, el olvido, Madrid, Trotta, 2003.

Rosen, G. «Nostalgia: A Forgotten Psychological Disorder», Clio Med. 10/1 (1975), pp. 28-51. 
San Martín, J. Antropología filosófica II, Madrid, UNED, 2015.

Scheuchzer, J. J. «De nostalgia», De Bononiensi Scientiarum et Artium Instituto atque Academia Commentarii I (1731), pp. 307-313.

Sedikides, C. y T. Wildschut, "Past forward. Nostalgia as a motivational force», Trends in cognitive sciences 20/5 (2016), pp. 319-321.

Sedikides, C., Wildschut, T. y D. Baden. «Nostalgia: Conceptual issues and existential functions», en J. Greenberg, S. Koole y T. Pyszczynski (Eds.), Handbook of experimental existential psychology, Nueva York, Guilford, 2004, pp. 200-214.

Sedikides, C., Wildschut, T., Routledge C. y J. Arndt, «Nostalgia counteracts self-discontinuity and restores self-continuity", European J. of Social Psychology 45/1 (2015), pp. 42-61

Starobinski, J. «The Idea of Nostalgia», Diogenes 54 (1966), pp. 81-103.

Tones, J. «49 películas y series que nos harán celebrar la llegada de 2019». Xataka, 3/1/2019. [en línea]: https://www.xataka.com/cine-y-tv/49-peliculas-series-que-nos-haran-celebrar-llegada-2019

Touraine, A. Un nuevo paradigma para comprender el mundo de hoy, Barcelona, Paidós, 2005.

Trigg, D. «From anxiety to nostalgia: a heideggerian analysis», Existential Medicine: Essays on Health and Illness, Londres, Rowman \& Littlefield. (2018), pp. 43-57.

Valero, C. P. e I. Zacipa. "El pasado está de moda. La nostalgia del consumo", en Zacipa, I., Tur-Viñes, V. y J. Segarra-Saavedra (Eds.), Tendencias publicitarias en Iberoamérica. Diálogo de saberes y experiencias, Alacant, UA, 2016.

Vattimo, G. El fin de la modernidad. Nibilismo y hermenéutica en la cultura posmoderna, Barcelona, Gedisa, 2015.

Villaseñor, S. «Porqué la nostalgia es la tendencia más fuerte de la última década", Elle, 18/10/2018. [En línea]: https://elle.mx/moda/2018/10/18/ nostalgia-de-moda-jovenes/

Wildschut, T., Sedikides, C. y C. Routledge, «Nostalgia - from cowbells to the meaning of live», The Psycologist 21 (2008), pp. 20-23.

Yotka, S. «La nostalgia es, oficialmente, la tendencia de moda más importante de 2018», Vogue, 19/12/2018. [En línea]: https://www.vogue.mx/ moda/tendencias/ articulos/tendencias-de-moda-2018-nostalgia-segunbusquedas-de-google/14309

Zambrano, M. Hacia un saber sobre el alma, Madrid, Alianza, 1989.

Zirión Quijano, A. "Coloraciones emotivas y temples anímicos en los Estudios acerca de la estructura de la conciencia de Husserl», Isegoría. Revista de filosofía moral y política 60 (2019), pp. 123-145. 